\title{
DOMINANCE OF ORDINAL SUMS OF THE LUKASIEWICZ AND THE PRODUCT TRIANGULAR NORM
}

\author{
PETER SARKOCI
}

\begin{abstract}
In this paper we provide a simple characterization of the dominance in two classes of continuous triangular norms. In particular, we solve the dominance of (i) ordinal sum t-norms that use the Łukasiewicz t-norm as the only summand operation and (ii) ordinal sum t-norms that use the product t-norm as the only summand operation. In both cases, the dominance relation is characterized by a simple property of the idempotent elements of the dominating t-norm. We also introduce the notion of the axis of a conjunctor and, as a side result, we characterize dominance of continuous conjunctors in terms of their axes.
\end{abstract}

Mathematics subject classification (2010): 26D07 39B62.

Keywords and phrases: Iterated functional inequality, dominance, subadditivity, ordinal sum t-norm.

\section{REFERENCES}

[1] C. Alsina, M. J. Frank, And B. Schweizer, Associative Functions: Triangular Norms and Copulas, World Scientific Publishing Company, Singapore, (2006).

[2] U. Bodenhofer, A Similarity-based Generalization of Fuzzy Orderings, Universitätsverlag Rudolf Trauner, Schriftereihe der Johannes-Kepler-Universität Linz, Volume C 26, Linz, (1999).

[3] B. De Baets And R. Mesiar, Pseudo-metrics and T-equivalences, J. Fuzzy Math., Vol. 5, 2 (1997), p. 471-481.

[4] B. De Baets and R. Mesiar, T-partitions, Fuzzy Sets and Systems, Vol. 97, 2 (1998), p. 211-223.

[5] D. Dubois And H. Prade, New Results about Properties and Semantics of Fuzzy-Set Theoretic Operators, p. 59-75, in Fuzzy sets: Theory and Applications to Policy Analysis and Information Systems (P. P. Wang and S. K. Chang Eds.) Plenum Press, 1980, New York.

[6] F. Durante And P. L. PaPini, Componentwise Concave Copulas and their Asymmetry Kybernetika, Vol. 45, 6 (2009), p. 1003-1011.

[7] E. Hille AND R. S. Phillips, Functional Analysis and Semi-groups, American Mathematical Society, Providence, Rhode Island, (1957).

[8] E. P. Klement, R. Mesiar, And E. Pap, Triangular Norms, Kluwer Academic Publishers, Dordrecht, (2000).

[9] G. Mayor And J. Torrens, On a Family of $t$-Norms, Fuzzy Sets and Systems, Vol. 41, 2 (1991), p. 161-166.

[10] R. MesiaR AND S. SAMINGER, Domination of Ordered Weighted Averaging Operators over t-norms, Soft Computing, Vol. 8, 8 (2004), p. 562-570.

[11] H. P. Mulholland, On Generalizations of Minkovski's Inequality in the Form of a Triangle Inequality, Proc. London Math. Soc., Vol. 51, 1 (1950), p. 294-307.

[12] A. Pradera AND E. Trillas, A note on pseudometrics aggregation, Int. J. General Systems, Vol. 31, 1 (2002), p. 41-51.

[13] S. Saminger, B. De Baets and H. De Meyer, On the Dominance Relation Between Ordinal Sums of Conjunctors, Kybernetika, Vol. 42, 3 (2006), p. 337-350.

[14] S. Saminger, B. De Baets And H. De Meyer, A Generalization of the Mulholland Inequality for Continuous Archimedean t-norms, J. Math. Anal. Appl., Vol. 345, 2 (2008), p. 607-614.

[15] S. Saminger, B. De Baets And H. De Meyer, Differential Inequality Conditions for Dominance Between Continuous Archimedean t-norms, Math. Inequal. Appl., Vol. 12, 1 (2009), p. 191-208. 
[16] S. Saminger, R. Mesiar and U. Bodenhofer, Domination of Aggregation Operators and Preservation of Transitivity, Internat. J. Uncertain. Fuzziness Knowledge-Based Systems, Vol. 10, 1 (2002), p. 11-35.

[17] S. Saminger And P. Sarkoci, Dominance of Ordinal Sums of $T_{\mathbf{L}}$ and $T_{\mathbf{P}}$, Proceedings of the $5^{\text {th }}$ EUSFLAT Conference, Vol. 1, 2007, Ostrava. p. 35-39.

[18] S. S Aminger, P. SAR Koci AND B. De BAETs, The Dominance Relation on the Class of Continuous T-Norms from an Ordinal Sum Point of View, Lecture Notes in Artificial Intelligence, Vol. 4342, 1 (2006), p. 334-354.

[19] B. Schweizer And A. Sklar, Probabilistic Metric Spaces, North-Holland, New York, (1983).

[20] P. SAR KOCI, Dominance is not Transitive on Continuous Triangular Norms, Aequationes Mathematicae, 3, Vol. 75, (2008), p. 201-207.

[21] R. M. TARdiff, Topologies for Probabilistic Metric Spaces, Pacific J. Math., 1, Vol. 65, (1976), p. 233-251.

[22] L. Valverde, On the Structure of F-indistinguishability Operators, Fuzzy Sets and Systems, 3, Vol. 17, (1985), p. 313-328. 